\title{
A Unique Case of a Child with Two Inherited
}

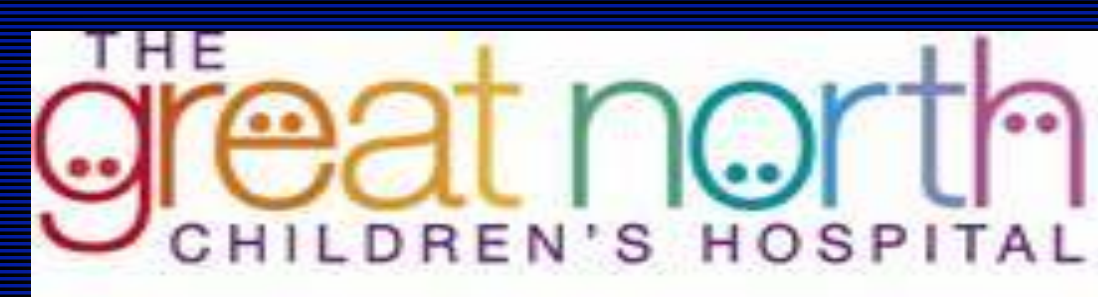

The Newcastle upon Tyne Hospitals W/HS

NHS Foundation Trust

\section{Salt-Losing Conditions}

DS Gurudutt ${ }^{1}, \mathrm{H} \mathrm{McCabe}^{2}$, C O'Brien${ }^{2}$, DSF Matthews ${ }^{1}$

Dept of Paediatric Endocrinology, ${ }^{2}$ Dept of Paediatric Respiratory Medicine

\section{Introduction}

Salt losing conditions can be challenging to manage well during infancy and childhood. Prolonged sodium depletion is known to be associated with growth failure and other problems in young animals ${ }^{1}$. We describe a unique case of a child with both Salt-Wasting 21-Hydroxylase Deficiency (SW21OHD) and Cystic Fibrosis (CF)

\section{Presentation \& Diagnosis}

A male infant, $A B$, birth weight $3500 \mathrm{gm}(-0.2 \mathrm{SDS})$, presented with saltwasting crisis on D9 of life with weight loss (12\%), hyponatraemia

$(120 \mathrm{mmol} / \mathrm{L})$ and hyperkalemia $(8.4 \mathrm{mmol} / \mathrm{L})$.

Serum 17-hydroxyprogesterone (17OHP) was $>1000 \mathrm{nmol} / \mathrm{L}$. Genetic analysis indicated he was a compound heterozygote with 2 pathogenic mutations including a deletion/gene-to-pseudogene conversion and a c955C $>$ T. A diagnosis of SW21OHD was made.

Neonatal screening confirmed the co-existence of CF with genotype $\triangle F 508 / A 455 E$ (some preservation of chloride transport). AB's sweat chloride was $73 \mathrm{mmol} / \mathrm{L}$ and his stool elastase was normal (pancreatic sufficient)

\section{Management}

At diagnosis $A B$ was established on treatment with Hydrocortisone $(\mathrm{HC})$ $13 \mathrm{mg} / \mathrm{m}^{2} /$ day, Fludrocortisone (FC) 300 micrograms/day together with salt ( $\mathrm{NaCl}$ ) supplements $4 \mathrm{mmols} / \mathrm{kg} /$ day and Flucloxacillin.

Serial measurements of serum sodium $\left(\mathrm{Na}^{+}\right)$, potassium $\left(\mathrm{K}^{+}\right)$and systolic blood pressure (BP) were within normal limits throughout infancy and early childhood

However, plasma renin activity (PRA) was elevated, particularly following the introduction of proprietary low-salt weaning foods. This was associated with poor weight gain, reaching a nadir of $7.5 \mathrm{~kg}(-2.3 \mathrm{SDS})$ at $0.9 \mathrm{yrs}$. FC dose was increased to $400 \mathrm{mcg} / \mathrm{d}$ but with little beneficial effect.

Salt supplements were increased gradually, reaching a maximum daily salt intake of $11 \mathrm{mmol} / \mathrm{kg} /$ day at around $2.2 \mathrm{yrs}$. FC dose was decreased gradually to $200 \mathrm{mcg} /$ day in view of its potential growth suppressing effects.

At 4.1yrs, AB's weight had increased to $16.7 \mathrm{kgs}$ (-0.1SDS), height $100.7 \mathrm{cms}(-0.7 \mathrm{SDS})$, height velocity $6.6 \mathrm{cms} / \mathrm{yr}$ and PRA was within normal limits.

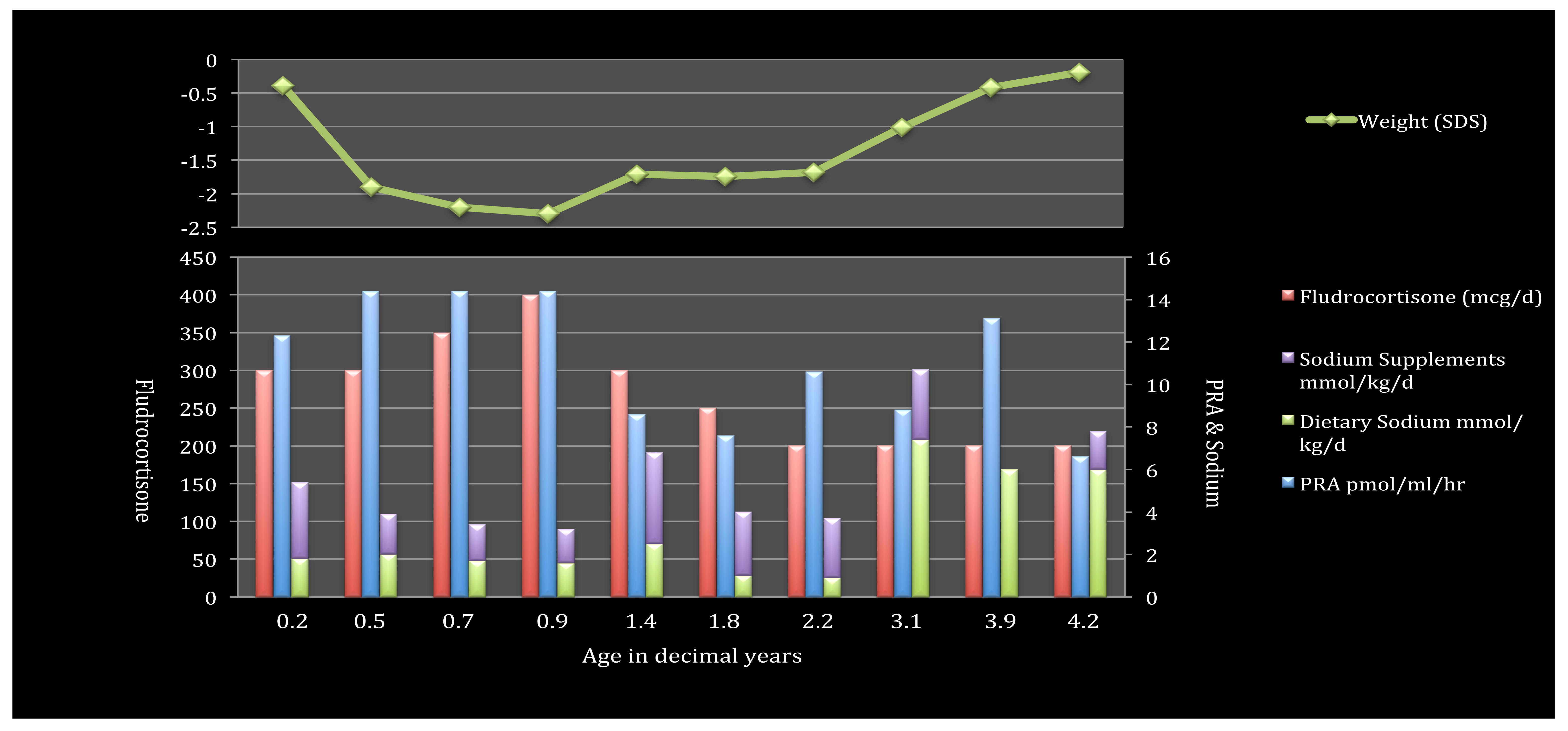

\section{Discussion}

In our tertiary paediatric centre, infants with SW21OHD or CF are commenced on $\mathrm{NaCl}$ supplements $(2-4 \mathrm{mmols} / \mathrm{kg} / \mathrm{d})$ at diagnosis and these are continued until the child is fully weaned.

Our child, $A B$, grew poorly during infancy and early childhood despite provision of fludrocortisone, hydrocortisone \& $\mathrm{NaCl}$ supplements. The PRA was persistently elevated suggesting chronic sodium depletion despite normal values of $\mathrm{Na}^{+}, \mathrm{K}^{+}$and systolic BP. Increasing the dose of fludrocortisone was not effective in reducing PRA and achieving weight gain. $A B$ has required continuing $\mathrm{NaCl}$ supplementation, which is provided as commercially available salt sachets (each containing about $13 \mathrm{mmols} \mathrm{NaCl}$ ).

\section{Conclusions}

This case highlights a number of important issues:

1.The importance of monitoring salt intake and ensuring adequate salt intake in infants with salt-wasting conditions to allow optimal growth

2.The relationship between salt intake, FC dose and PRA and their relative roles in the optimal management of SW21OHD.

3.The possible role of salt depletion in growth failure in infants and children with cystic fibrosis.

The endocrine \& metabolic adaptation to salt depletion in CF patients has not been well studied and requires further evaluation.

\section{References}

1. SJ Wassner. Pediatr. Nephrol.1991; 5:501-504 